\title{
INTESTINAL PARASITIC INFESTATION IN HEALTHY SCHOOL CHILDREN OF LALITPUR DISTRICT
}

Shrestha $B^{1}$

\section{ABSTRACT}

Stool sample of $\mathbf{5 1 5}$ healthy urban and rural school children of Lalitpur district in the age group between 7-12 were collected and tested for the presence of ova and cyst of helminths and protozoan. A total of $\mathbf{8 1 . 9 4 \%}$ of the children were found infested with parasites. Both rural and urban children exhibited similar pattern of infestation. No association of the infestation with the localities is observed $\left(X^{2}=2.17\right)$. A very great prevalence of helminths especially Ascaris lumbricoides and Trichuris trichuria compared to protozoan was observed. Among rural and urban children, total $A$. lumbricoides infestation was $73.45 \%$ and $71.66 \%$ and $T$. trichuria infestation was $27.27 \%$ and $37.91 \%$ respectively. $78.36 \%$ and $84.07 \%$ of the male, and $92.45 \%$ and $73.72 \%$ of the female children from the urban and rural respectively were found infested with the protozoan and helminths. The infestation was not associated with particular gender $\left(X^{2}=0.1121\right)$. The helminth parasitic infestation rate is very high compared to protozoan parasites among the school going children, hence the parents and the children should be made aware of the problem.

Key Words: Helminths, Protozoan, Lalitpur, Children, Prevalence, Water.

\section{INTRODUCTION}

The human intestinal parasites in people with gastroenteritis have been reported in many studies. However, the study on healthy school children is not reported often; therefore, this study is based on healthy asymptomatic carriers of 7-12 years of age of urban and rural area of Lalitpur district where water supply is neither good not adequate. Further more, hygiene of people is poor.

The source of infestation is the carrier or the infested person and mode of transmission is faecal to oral in most of the cases. The faecal matter contaminates the water and soil. The consumption of such water and food contaminated with soil and

1. Trichandra College, Kathmandu, Nepal.

Address for correspondence : Bidya Shrestha, Lecturer, Department of Microbiology

Tri-chandra College, Kathmandu, Nepal.

Email: bshrestha@enet.com.np 
handled by unclean hands, when consumed the ova present in them enter the gastrointestinal tract and there they hatch.

When the number of parasites is small the infestation may not be severe but there are critical limits for many parasites which when exceeded cause damage to the tissue of the host. ${ }^{1}$ Infestation with intestinal roundworm (A. lumbricoides) constitutes the largest incidents of helminthiasis in human being. Children are generally more heavily infested than adults and are therefore more likely to suffer from the pathological consequences of these infestations. ${ }^{2,3}$ Weiss E L mentions that infection with Ascaris lumbricoides is rarely fatal but death may occur because of mechanical intestinal obstruction. ${ }^{2}$ Therefore, detection and treatment of asypmtomatic carrier of helminth and protozoal parasites is of great value in protection of children from the different pathological consequences.

In Nepal different reports on intestinal parasitic infestation among patients attending hospitals to detect the cause of diarrhea, dysentery etc. are produced by various researchers. According to Rai et al (1995) $29.1 \%$ to $44.2 \%$ of the patients attending the Tribhuvan University Teaching Hospital during 1985-1994 had intestinal parasitic infestation. Helminths were detected more frequently than the protozoans and children had higher rate of intestinal parasite infection rate than the adults. ${ }^{3}$ A. lumbricoides topped the list followed by hookworm and Trichuris trichuria. In contrast Shakya H R (1999) has reported that in child patients seeking treatment in Tribhuvan University Teaching Hospital parasitic infestation was found in $10.6 \%$ with protozoan parasites in high prevalence than helminths. ${ }^{4}$ In the other hand, Chand A B reported that among the child patients attending Kanti Children Hospital 27.94\% were found infested with pathogenic parasites, among which $16.91 \%$ were protozoan parasites and $11.03 \%$ were the helminths. Among helminths $A$ lumbricoides was in greatest prevalence $(6.62 \%)$ followed by hook worm (3.31\%)and T. trichuria $(1.1 \%) .{ }^{5}$ Yet another pattern of parasitic infestation has been reported by Piya et al (2001), where 41.30 $\%$ of children attending Kanti Children Hospital were reported to be infested by intestinal parasites with Entamoeba histilytica topping the list 27.17 $\%$ followed by A lumbricoides $(9.23 \%)$ and Giardia lambia $(3.8 \%){ }^{6}$

\section{MATERIALS AND METHODS}

Stool samples of 515 healthy school children between 7-12 years were collected. Of these, 275 children were from rural areas of Lalitpur viz. Imadole, Tikathali, Oochu, Damaitar and Sangaun; and 240 children were from urban areas of Lalitpur viz. Balkumari and outskirts of Lalitpur. Among rural children $57 \%$ (157) were male and $43 \%$ (118) were female. Similarly among the urban children $56 \%$ (134) were male and 44\% (106) were female.

The children were mostly from the uneducated families and were not satisfactory in sanitation. Their food habit was normal to that of working people with consumption of meat including buff and chicken. Though they had toilet in their school and homes, their sense of hygiene was not as good as it should have been. The most striking part is that they all consumed well water in home as well in school, which is in close proximity to the toilets.

Those children having diarrhea 2 weeks back were excluded but few children having two loose stools per day were included. More than 3 loose stools per day or passage of 3 stools in addition to normal or mothers' complaint of diarrhea were considered as diarrhea. 
Questionnaire- Questionnaire were filled for all children which included age, gender, locality, source and treatment (domestic) of water, the dietary habit, hygiene, and socioeconomic condition of the family.

Examination- The stool samples were processed and examined as per standard methodology described by World Health Organization. ${ }^{7}$

Macroscopic examination- The stool samples were examined macroscopically for the presence of frank blood, mucus, color, and consistency.

Microscopic examination- Microscopic examination was performed as per standard methodology. The stool samples were examined by mixing a speck of stool with a drop of physiological saline under a microscope with 10x. The suspected ova, cyst, trophozoites were confirmed by viewing with 40x.

Iodine mounts were prepared when necessary, here iodine solution replaces the physiological saline and the remaining procedure is the same. The samples showing no ova or cyst were examined by concentration method, the sodium chloride floatation method.

\section{RESULT}

A very large proportion of children $81.94 \%$ (422) were found infested with different parasites helminths and protozoans. Among them $84.58 \%$ (203) of urban and 79.63\% (219) of rural children were infested (See Table No.1). Obviously, greater occurrence of helminths compared to that of protozoan was observed. Among helminths $A$. lumbricoides was the most prevalent one followed by $T$. trichuria in both rural and urban localities (See Table I). In one case cestode - Hymenolepis nana was also found.
Table I

Parasites among urban and rural children.

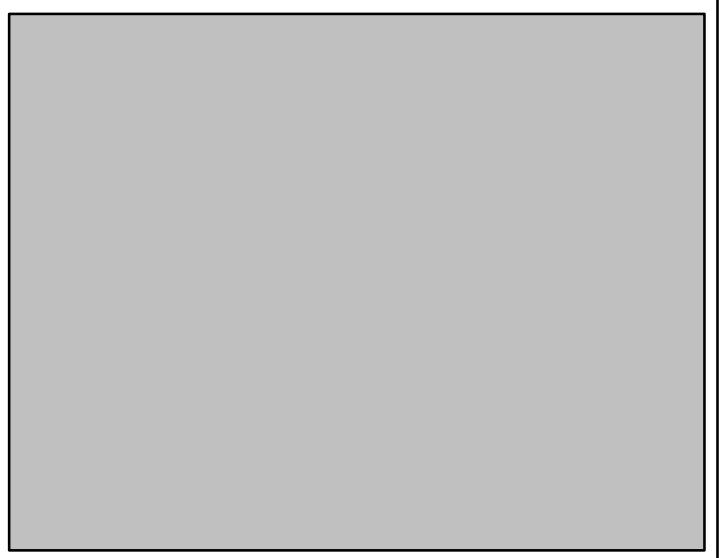

Mixed infestation was found in $25.43 \%$ of the children. The most prevalent mixed infestaion was between A. lumbricoides and T. trichuria. (See Table No II)

Table II Mixed Infestation

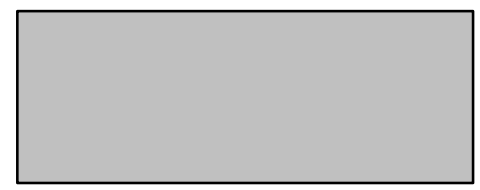

Number in parenthesis is the total number tested.

The infestation observed was high and at the same time there was variation of its occurrence among the male and female children from urban and rural areas. In the urban area out of 134 male children, $78.36 \%$ (105) were found infested, whereas it was $84.07 \%$ (132) among 157 in rural area. In the same way, the infestation was observed $92.45 \%$ (98) in female children (106) from urban area and was $73.72 \%$ (87) among 118 in rural area. (See Table III) This indicates that infestation is in greater occurrence among the male children in rural area and female in urban area. However, the infestation is not associated with the gender $\left(\mathrm{X}^{2}=0.1121\right)$ and with the locality they live in $\left(\mathrm{X}^{2}=2.17\right)$. 
Table III

Infestation among male and female children

Number in parenthesis is the total number tested.

\section{DISCUSSION AND CONCLUSION}

In this study of parasitological infestation among healthy school children of Lalitpur district, $81.94 \%$ were found infested. This study was focused on parasitic infestation among children as they are more commonly and heavily infested than adults due to their habit (e.g. directly or indirectly consuming soil). ${ }^{2,3}$ This finding is consistent with the findings of Rai and Gurung where $69 \%$ of the school children in Birgunj were reported infected by intestinal parasites. ${ }^{8}$

Since both urban and rural children were similar in their hygienic practice, dietary habit, socioeconomic condition (low), source of water (well mostly), they exhibit similar pattern of helminthic infestation. A. lumbricoides infestation was highest $(71.66 \% \& 73.45 \%)$ followed by $T$. trichuria $(37.91 \% \& 27.27 \%)$ in urban and rural area respectively. This finding correlates with the report of Weiss where he states 4 million people of US mostly in rural southeast are infected with $A$. lumbricoides and in developing countries more than 1 in 4 are infected (e.g. Southeast Asia $73 \%$, Africa $12 \%$, Central and South America $8 \%$ ). ${ }^{2}$ This present finding is also supported by Rai and Gurung where $35 \%$ of school children were found infected by A. lumbricoides, but no cases of $T$. trichuria was reported. ${ }^{8}$ The difference in percent prevalence between these two reports could be due to difference in localities, personal hygiene, water contamination etc. Chhetri has also reported a higher rate of parasitic infection in general school going children $70.5 \%$ and $70 \%$ compared to boarding school going children $44 \%$ and $40 \%$ who used the latrines built by Family Planning Association Nepal, in Kathmandu and Sunsari respectively. ${ }^{9}$

Protozoan infestation was observed very small compared to that of helminths. In a study reported by Rai et al. (1994), the annual incidence of intestinal parasitic protozoan infection among hospital attending patients seeking detection of intestinal parasites in Tribhuvan University Teaching Hospital ranged from 3.3-13.6 \%. ${ }^{10}$ The difference between this report and present finding with low prevalence of the protozoan parasites could be due to the fact that the subjects are healthy in this present study. There are some other reports of helminthic infestation among children having gastroenteritis. But the occurrence of helminths in them is quite low compared to the healthy carriers observed in this study. ${ }^{4,5,6}$ The infestation by $A$. lumbricoides, $T$. trichuria and their mixed infestation observed in this study are very high compared to the reports of Shrestha, Thapa and Devkotaand Blangero $(36 \%, 30.94 \%$ and $27.24 \%$ of people with gastroenteritis were infested with A. lumbricoides respectively). ${ }^{11,12,13}$

Mixed infestation by two helminths $A$. lumbricoides and T. trichuria was also high 25.43 $\%$; (25\%) among urban and (22.18\%) among rural children in present study. Since the ova of $A$. lumbricoides and $T$. trichuria are excreted by the infected person thus contaminating the soil and the water, vegetable etc. that comes in its contact, they are ingested along with contaminated water, soil and via contaminated fingers. All the children under the test were poor in hygiene \& sanitation and consumed water from wells or taps without domestic treatment before consumption. Even in school they consumed the water from wells without treatment. Water, the source of infection in Kathmandu valley (Lalitpur, Bhaktapur and 
Kathmandu) has been reported contaminated with sewage due to running of water pipe and sewage line close together, water flowing intermittently causing negative pressure thus sucking fluids and air from leaky pipe lines. ${ }^{14,15}$

The infestation was found not associated with any gender or the locality. However, Weiss suggests that no racial predilection is known, but in Nepal, genetic predisposition is described in a study of families in Nepal. ${ }^{2}$

The protective immune mechanism seems to have less value against helminths. The helminths go through a complex life cycle and protective immune mechanism appears to act only at an early stage in the life cycle. ${ }^{16}$

The carrier children being the possible source of infestation and to prevent them from getting pathological disorder they were prescribed with proper medicament. The children were advised to treat the well water prior to consumption either by filtering or boiling or both.

From present study it is evident that the helminth parasites are in great prevalence among the healthy school going children. However, the infestation depends on the hygiene and sanitation of people involved, water contamination, health education status etc.

\section{REFERENCE}

1. KhalequeA. ATextbook of Pathology; vol. I; Dhaka, Ludhok Prakashan. 1988; 116-161

2. Weiss E L. Ascaris lumbricoides, eMedicine Journal. 2001; 2: No 3.

3. Rai SK, Bajracharya K, Budhathoki S et.al. Status of intestinal parasitoses at TUTeaching Hospital, J Inst Med. 1995; 17:134-142.
4. Shakya H R. Thesis on Prospective Study on Aetiology of Childhood Diarrhea based on Clinical features and Laboratory Diagnosis. 1999.

5. Chand A B. Thesis on A Prospective Study on Aetiological Agents of Diarrheal Disease in Children in Relation to Parasites and to Determine the Antibiotic Sensitivity Pattern of I solates. 2000.

6. Piya S, Adhikari S, Rajbhandari T P. A Study on Diarrhea in Children in Relation to Behavioral and Environmental Factor, J Sci Tech. 2001:3:85-88.

7. WHO.; Parasitology; Geneva, WHO. 1991.

8. Rai S K and Gurung C K. Intestinal Parasitic Infection in High School Level students in Birgunj City, J Inst Med. 1986; 8: 33-38.

9. Chhetri M K. Parasitic Infestation in Nepal. International symposium on Infectious and Tropical Disease. 1996; March 20-21, 28

10. Rai S K, Budhathoki S, Bajracharya K. et al. Prevalence of Intestinal Protozoan Parasitic Infection in Nepal, The Hyogo J ournal of Medical Technology. 1994; 14: No 4, 39-44.

11. Shrestha Y B. Experience in Bode Bhaktapur; Nepas free Medical Cinic in Souvenir II nd Nepalese congress of Paediatrics; Health Care for Rural Children, Nepal. 1984; 105-115.

12. Thapa CL, Devkota R P. Kaligandaki Hospital; An Example of Community Based Health, J NMA. 1991; 29: 291-300.

13. Blangero $\mathrm{W}$ et al. Helminthic infection in J iri, Nepal, Analysis of age and ethnic group effects; J Inst. Med. 1993; 15: 210-216.

14. Adhikari R K, Rai S K, Pokhrel B M et al. Bacteriological Study of Drinking Water of Kathmandu Valley, J Inst Med. 1986; 8:313-316.

15. Sharma A P. Quality of Drinking Water of Kathmandu Valley, J Inst.Sci. 1978; 15-22.

16. Weir D M. I mmunology; An Outline for Students of Medicine and Biology, $5^{\text {th }} \mathrm{Ed}$, Edinburgh, Churchill Livingstone. 1983; 107-149.

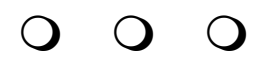

